\title{
Cultured Meat: The Upcoming Meat Production having Sustainable Benefits over Conventional Meat Production: A Review
}

\begin{abstract}
A Need for meat is rising day by day and the production of poultry, cows, pigs and fisheries is reduced as there is no good commercial production. Wider livestock production is becoming unavailable on a global scale in requisites of welfare of animals, ecological sustenance and human health conditions. Choices for cultured meat are being explored using innovative techniques like stem cells, Embryonic Stem Cells, Induced pluri potent stem cells [(iPSC) derived from skin or blood cells of an animal that have been reprogrammed back into an embryonic-like pluripotent], Totipotent stem cells [immature cells capable of giving rise to any cell type or (of a blastomere) a complete embryo], pluripotent stem cells (immature cells capable of giving rise to several different cell types), satellite cells or myoblasts, etc. In these methods, animal tissue is grown in a controlled surroundings using culture cell technology. Several attempts are made to develop different types of media and techniques like the self-organizing techniques and scaffold-based techniques to advance the growth of the cell. Cultured meat is also called in various names like 'clean meat', 'in-vitro meat', or 'artificial meat'. The concept is in the budding stage of commercialization. Therefore, along with the improvement in technical phase there is a lot of work is being carried on in the developmental aspects of biological, commercial, social, economic and ethical.
\end{abstract}

Key words: Cultured meat, Human health conditions, Stem cells, Techniques.

Meat is a imperative source of protein, fat, iron and many other nutrients required for the humans since from ages. Each year, more than 60 billion animals are reared in commercial conditions in meat production. Animals grown in commercial way like poultry farms, goat farms, cattle farms, piggery, fisheries etc. have resulted in causing and spreading of frequent animal diseases like "Madcow", "Bird Flu", "Scombroid", "Foot and Mouth disease" which has even got transmitted to humans when not disposed in care but such meat were forced to slaughtered, marketed and consumed. Animal husbandry has another side upshot that is choking the Earth by using about $70 \%$ of agricultural land for the purpose of fodder which has adverse effects on natural resources such as the depletion of freshwater reservoirs, biodiversity hammering, soil erosion and obliteration of habitats and so on. Farm animals rising for meat, eggs and milk generates around $15 \%$ of global greenhouse gas emissions, the second biggest source of emissions higher than all combined transport reported by Valin et al. (2014). India where the per capita meat consumption in 2013 was approximately the same as in 1961 at less than $4 \mathrm{~kg}$ per person. To resolve the problems related to meat consumption on a global scale as well as to meet the meat requirement demand, cultured meat or lab-grown meat would play anessential role in the novel era. The concept of cultured meat was popularized by Jason Mathenyin in early 2000. In 2013, Mark Post created the first lab-grown burger patty. Cultured meat production involves a multidisciplinary approach that includes biotechnology, tissue engineering and molecular biology to
Indian Institute of Food Processing Technology, Ministry of Food Processing Industries, Govt. of India, Thanjavur-613 005, Tamil Nadu, India.

Corresponding Author: R. Akshay Patil, Indian Institute of Food Processing Technology, Ministry of Food Processing Industries, Govt. of India, Thanjavur-613 005, Tamil Nadu, India. Email: akshaynayaka1111@gmail.com

How to cite this article: Patil, R.A., Bhavana, A., Patil, B.R. and Deepak (2022). Cultured Meat: The Upcoming Meat Production having Sustainable Benefits over Conventional Meat Production: A Review. Agricultural Reviews. DOI: 10.18805/ag.R-2333.

Submitted: 20-07-2021 Accepted: 11-10-2021 Online: 17-01-2022

generate a novel design to produce proteins and fats and tissues. The start-ups developing cultured beef, pork, poultry and seafood are Mosa Meat, Memphis Meats, Super Meat and Finless Foods using contemporary techniques. While research is ongoing, the attempt was made to fabricate the cultivated meat for space flights. NASA cultured muscle tissue (obtained from common goldfish (Carassius auratus), ranging 3-10 cm in length, in Petri dishes (Benjaminson et al., 2002). Muscle tissues cultured in crude cell extracts enhanced in cell mass. Such cells were later washed, dipped in olive oil and spices, coated with breadcrumbs, fried and tested with a taste panel which concluded that the product was palatable. One of the essential techniques of artificial meat production was to obtain and grow muscle tissues in an acceptable medium and to harvest them by Benjaminson et al. (2002). In vitro sophisticated meat engineering and 
tissue engineers have been involved in the assortment process, putting adult cells on scaffolds, developing them in bioreactors and using cultivated cells to produce muscle tissue investigated by Catts et al. (2002). Definite programs aimed at with the propagation of stem cells by putting them on top of each other and by means of inkjet techniques to spew cell materials on sheets or other structures. Bhat and Bhat (2011). Researchers of the Cultured Beef Project remove muscle cells from the shoulder of a cow and nourish the cells with a nutrient mixture in a Petri dish and they grow into muscle tissue. It took three months to cultivate the beef using stem cells from a cow's shoulder. By tissue engineering technique it is possible to obtain tons of meat from a few starter cells. Mosa Meat, a Dutch compsany, launched its first hamburger in London in 2013. The burger included five ounces of grown meat (beef) patty, cooked and analyzed by a panel of sensory experts in London, who found it tasted nearer to a regular burger. For this burger, the financial cost was over $\$ 330,000$. The event encouraged consumers, particularly those concerned with animal welfare, to sustain the commercial introduction of such meat products by Stephens et al. (2018). The company ' Super Meats 'has been functioning in Israel with the Hebrew University of Jerusalem for several years and recent news reports suggest that three Israeli artificial meat companies Super Meat, Future Meat Technology and Meat the Future will benefit from the $\$ 300$ million trade conformity signed between China and Israel (Roberts 2017).

\section{Origin}

The thought of cultured meat for human consumption was written long back by Winston Churchill in essay 'Fifty Years Hence' later published in book "Thoughts and Adventures" in 1932. He declared that "Fifty years hence we shall escape the illogicality of growing a whole chicken in order to eat the breast or wing by growing these parts separately under a suitable medium". Although, the initiative of cultured meat was predicted two years earlier by a writer and conservative politician Frederick Edwin Smith, $1^{\text {st }}$ Earl of Birkenhead, who predicted that "It will no longer be necessary to go to the profligating length of rearing a bullock in order to eat its steak. From one 'parent' steak of choice tenderness, it will be potential to grow as large and as juicy a steak as desired" by Ford (2010). In 1943, Rene Barjavel, a French science fiction author described artificial production of meat in restaurants in his novel 'Ravage' later on translated as 'Ashes, Ashes' in 1967. Alexis Carrel managed to keep a piece of embryonic chick heart muscle alive and beating in a Petri dish in 1912. The muscle tissue grew significantly. Willem Van Eelen of the Netherlands autonomously had the idea of using tissue culture for the generation of cultured meat. It took until 1999 before van Eelen's theoretical idea was patented as the concept of stem cells and artificial culture of cells was yet to emerge. Symbiotic harvested muscle biopsies from frogs and kept these tissues alive and growing in culture dishes reported by Catts and Zurr (2002). Foreseeing on the infection risk associated with serum- based media, other research initiatives have also achieved keeping muscle tissue alive in a fungal medium. Benjaminson et al. (2002) cultured muscle tissue from the common goldfish (Carassius auratus) in Petri dishes aiming to discover the possibilities of culturing animal muscle protein for long term space flights. The cultured muscle explants, or biopsied muscle tissue, obtained in the study were washed, dipped in olive oil with spices, covered in breadcrumbs and fried. A test-panel judged these processed explants and agreed that the product was acceptable as food Benjaminson et al. (2002). In 2013, the world's first in vitro meat based burger was cooked and tasted by a sensory panel in Riverside Studios in London. The burger contained five-ounce burger patty produced by using laboratory grown beef worth more than $\$ 330000$. It took only three months to grow up the beef in the laboratory, using stem cells harvested from a cow's shoulder. The cultured meat produced was reported to be colourless and more like chicken. So a bit of red beet root juice and saffron was added to colour the meat. The sensory panel comprised of Mark Post, the scientist who created the cultured meat in his laboratory at Maastricht University in the Netherlands, Josh Schonwald, the American author of "The Taste of Tomorrow" and Hanni Rützler, an Austrian nutritional scientist. The panellists said that the burger tasted, "almost" like a traditionally cultivated one. No one argued the meat out; no one cringed. The professor Mark Post said that he would expect to see cultured meats in supermarkets in 10 to 20 years.

\section{Production techniques}

\section{Source}

Scaffold technique used in cultured meat production Zuhaib Fayaz Bhat et al. (2015). Using a variety of techniques, varying from that which use scaffolds to those which rely on self-organization, meat is already cultured on small and early scales (Edelman et al. 2005). However, the production of highly-structured, unrefined meat faces significantly greater scientific challenges and a great deal of research is still need to establish a sustainable artificial meat culturing system on a business scale Bhat and Bhat (2011a). The different aim approaches for an in vitro meat production system, all of which are intended to overcome the dissemination barrier, range from those are at present in use (scaffold/cell culture based and self-organizing/tissue culture based) to the more speculative possibilities Bhat and Bhat (2011a, b).

\section{Scaffolding techniques}

A scaffold based in vitro meat production system would involve seclusion of embryonic myo-blasts or adult skeletal muscle satellite cells from the farm animals like cattle, poultry, sheep, pig, etc., which would be allowed to grow inside a stationary or rotating bioreactor using a plant sourcedevelopment medium. These cells would divide and subdivide for weeks and months together and would be finally differentiated into the muscle fibers onto a scaffold 
inside the bioreactor. Attached to a scaffold or carrier such as a collagen meshwork or microcarrier beads, stem cells fuse into myo-tubes, which can then differentiate into myofibers by introducing a variety of environmental cues Kosnik et al. (2003). The resulting myofibers may then be harvested, processed, cooked and consumed as emulsion or ground meat products (Fig 1). These scaffold-based techniques cannot produce highly structured meats like steaks but can be used to produce ground and boneless meats with soft consistency. However, cells can also be grown in substrates that allow for the development of "selforganizing constructs" that produce more rigid structures. Currently there are two detailed proposals which use cell culture for production of meat Boland et al. (2003); Zandonella (2003) and both these proposals are similar in nature and neither of the two has been tested Bhat and Bhat (2011a). These proposals are written by Willem Van Eelen who also holds a worldwide patent for this system Van Eelen et al. (1999) and Vladimir Mironov who has written the proposal for the NASA (National Aeronautics and Space Administration) Wolfson (2002). Vladimir Mironov's proposal uses a bioreactor in which cells are grown together with collagen spheres to provide a substrate onto which the myoblasts can attach and differentiate whereas Van Eelen's proposal uses a collagen meshwork and the culture medium is refreshed from time to time or percolated through the meshwork Bhat and Bhat (2011a, b).

\section{Self organising techniques}

Another potential method of creating in vitro meat utilizes explanted animal muscle tissue, a more ambitious approach to produce highly structured meats creating structured muscle tissue as self-organizing constructs Dennis and Kosnik (2000) or proliferating existing muscle tissue in vitro,

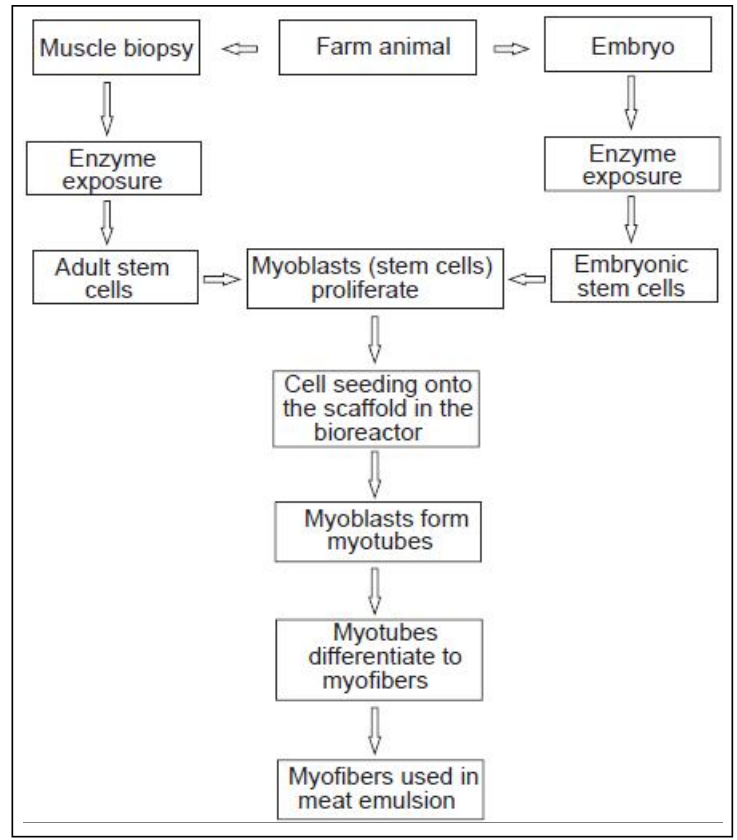

Fig 1: Scaffold technique used in cultured meat production. like Benjaminson et al. (2002) who cultured goldfish (Carassius auratus) muscle explants. Benjaminson et al. (2002) sought to test if co-cultures of cells derived from similar "adult muscle tissue" can adhere, attach and grow onto a muscle tissue explants "substrate". They took slices of goldfish tissue, minced and centrifuged them to form pellets, placed them in Petri dishes in a nutrient medium and grew them for 7 days. They utilized mature skeletal muscle explants because they contain muscle fibers as well as "all the cell types generally associated with muscle in vivo" Benjaminson et al. (2002). Benjaminson et al. (2002) tested a variety of growth media, such as fetal bovine serum, fish meal extract and various mushroom extracts, to see how each enhanced the growth of the explant muscle tissue and to seek alternatives to foetal bovine serum. Out of 48 cultures grown, $81 \%$ showed tissue adherence to the culture vessel after 2 weeks in culture, $63 \%$ demonstrated the selfhealing phenomenon and $74 \%$ of the cultures showed cell proliferation. The explanted tissue grew nearly $14 \%$ when using foetal bovine serum as the nutrient medium and over $13 \%$ when using Maitake mushroom extract. When the explants were placed in a culture containing dissociated Carassius skeletal muscle cells, explant surface area grew a surprising $79 \%$ in a week's time. The explants and their newly grown tissue looked like fresh fish filets which were marinated in olive oil and garlic and deep-fat fried and presented to a sensory panel for observation who reported that it looked and smelled good enough to eat Benjaminson et al. (2002); Britt (2002); Sample (2002); Hukill (2006). Selforganizing in vitro meat production may hold the promise to produce the highly structured meats as the explants contain all the tissues which make up meat in the right proportions and closely mimics in vivo situation, however, lack of blood circulation in these explants makes substantial growth impossible, as cells become necrotic if separated for long periods by more than $0.5 \mathrm{~mm}$ from a nutrient supply Dennis and Kosnik (2000). Vladimir Mironov suggested a branching network of edible porous polymer through which nutrients could be perfused and myoblasts and other cell types can attach Wolfson (2002). Such a design using the artificial capillaries for the purpose of tissue-engineering has already been proposed Zandonella (2003).

\section{Worth of cultured meat production}

Nutrition-related diseases, foodborne illnesses, antibioticresistant pathogen strains, use of resources and domestication of animals, environmental ramifications of raising livestock, including pollution from their excrement and gigantic emissions of methane causative to global warming are some of the serious consequences connected with traditional meat production systems and consumers have expressed rising apprehension over them Bhat and Bhat (2011a, b, c); Bhat et al. (2013). In the luminosity of the sizable pessimistic effect of current meat production on environment and human health, a feasible resolution lies with artificial meat production, a process that pretence to revolutionize human subsistence. Cultured meat production 
is one of the ideas that are being proposed to alleviate these ill effects associated with conventional meat production systems. The production of cultured meat may offer health and environmental advantages by reducing environmental pollution and water and land use associated with conventional meat production systems Bhat and Bhat (2011a, b, c). Thus, cultured meat production systems hold immense ecological assurance. Besides, reduces the environmental hazards, it will also lessen animal suffering considerably and will ensure sustainable production of customised, chemically safe and disease-free meat as the conditions in ancultured meat production system are controlled and manoeuvre (Bhat and Bhat 2011a, b).

Moreover, pleasing all the nutritional and hedonic needs of meat eaters, cultured meat has the latent to greatly decrease animal suffering and eating animals unnecessary Hopkins and Dacey (2008). It is potentially a much more dependable alternative as a product from a bioreactor does not come with all the vicissitudes of animals and is not bound to soil or place and opens up possibilities for novel places for production or for substitute land use. Furthermore, due to ill health, stress and uneven growth, animals are particularly unreliable as a raw material for meat production from a business and profit perspective (Bhat and Bhat 2011a, b).

\section{Purposeful and customised meat}

In comparison to the traditional meat, cultured meat can be customised to be healthier and functional by structuring the composition of the culture medium, the fat content and fatty acid composition of the cultured meat. Fat content can also be inhibited by supplementation of fats after production and to fabricate the ratio of saturated to poly-unsaturated fatty acids. Harmful saturated fats could be substituted by healthy fats, like omega-3 and omega 6 fatty acids. Furthermore, nutritional aspects of the meat can be enhanced by adding factors to the culture medium which might have anbeneficial effect on the health, like providing certain types of vitamins Van Eelen et al. (1999).

\section{Animal safety and wellbeing}

Summoned by activists of animal welfare and meat experts, cultured meat side steps the moral consequences of standard meat production, avoiding animal death completely by classically removing cells from the donor animal by conducting biopsy and cultivating cells in medium containing mushroom extract rather than animal blood serum Hopkins and Dacey (2008); Alexander (2011). Thus, cultured meat production system will decrease the use of animals and hypothetically, a single domesticated farm animal may be utilized to produce the world's meat supply Bhat and Bhat (2011a, b). If ten stem cells divide and distinguish continuously for two months, they could yield 50,000 metric tons of meat Bartholet (2011). Culturing embryonic stem cells would be ideal for this reason. Since, these cells have an almost infinite self-renewable capacity. In conjecture, one such cell line would be ample to factually feed the world Bartholet (2011).

\section{Declination in zoonotic and foodborne diseases}

Due to strict quality control rules, such as good Manufacturing practices, the occurrence of foodborne diseases could be considerably reduced and the chance of meat contamination would be lower in absence of a prospectively compromised organism. In adding up, the risks of exposure to other hazards associated with traditional meat production systems like use and production and imbalance of pesticides, arsenic, dioxins and hormones could be appreciably reduced.

\section{Rapid manufacture}

The current meat production systems are incompetent in terms of nutrient and energy utilization and also take long adaptation time with months for chickens,years for pigs and cows before the meat can be harvested and commercially available. In vitro system takes considerably lesser time to culture the meat and takes several weeks instead of months (for chickens) or years (for pigs and cows) before the meat can be harvested. As the time for which the tissue has to be maintained is much less, the amount of energy and labour required per $\mathrm{kg}$ of in vitro cultured meat is very much less.

\section{Diminution in resource utilization and ecological foot print}

The cultured production system is more environmental friendly and energy efficient than traditional farming. It will decrease the carbon footstep of meat products and further energy requirements will also be declined as unlike conventional meat where $75-95 \%$ of the feed given to an animal is lost because of metabolism and unpalatable structures like skeleton or neurological tissue, all the energy and nutrients will be utilized in the production of lean meat only Madrigal (2008); Alexander (2001); Bhat and Bhat (2011a, b). Bioreactors for artificial meat production do not need extra space and could be heaped up in a fabric hall. Thus in comparison to the traditional cattle farming; cultured meat production system would decrease the amount of land utilized to produce meat because artificial meat amenities could be built uprightly, taking up less land space and thus producers could place production centres in or near cities close to city-dwelling consumers which will further more decrease the transportation costs involved Kuang (2008); Datar and Betti (2010). According to some researchers, cultured meat production systems could diminish greenhouse gas emissions from raising livestock by as much as $90 \%$ and lessen use of land and water resources for raising meat up to $80 \%$ by Fox (2009); Schneider (2013). Tuomisto and de Mattos (2011) estimated that cultured meat involves $7-45 \%$ smaller amount energy than conventionally produced meat, $78-96 \%$ lesser emissions of greenhouse gases, 99\% lower land utilize and $82-96 \%$ lesser water use assuming that cyano-bacteria can be used as the source of nutrients and energy. According to a study carried out at the University of Oxford regarding the environmental impacts of cultured meat, if scientists grew the muscle cells in a 
culture of cyanobacteria hydrolysate, it would involve approximately 35-60\% lower energy use, 80-95\% lesser greenhouse gas emissions and $98 \%$ lower land use compared to traditionally produced meat products in Europe Bartholet (2011).

\section{Renovation of efficient nutrient and energy utilization}

In artificial meat production system will make use of the nutrients and energy required for growth, development and maintenance of muscle tissue only unlike conventional meat production where nutrients and energy is required for genetic and biological structures (bones, respiratory system, digestive system, skin and the nervous system) necessary for successful livelihood, locomotion and reproduction. Thus the nutritional costs for cultured meat will be significantly lesser than for conventionally cultured meat. Therefore, the financial advantages are yet undecided and it might be very well reduce in costs of resources, labour and land is compensated by the additional costs of a stricter hygiene regime, stricter control, computer management, etc.

\section{Societal support}

As cultured meat production would not involve the slaughtering of the animals and has potentially insightful environmental benefits; it will have a sturdy basis of hold in the scientific, animal welfare and ecological communities Hopkins and Dacey (2008); Schneider (2013).

\section{Afforestation and natural habitat}

The drastic reduction in land use unlocks the vision that much of these lands may be utilized for other purposes or just returned to wild life which may facilitate in restoration and Afforestation for and be a natural habitat for many endangered species.

\section{Accessibility of exotic meat}

As cultured meat production system uses stem cells for the production of meat, in theory, cells from captive rare or endangered animals or even cells from samples of extinct animals could be used to produce exotic meats in bioreactors. Thus exotic meats could be produced commercially without any threat to the existence of the species. Conventional global trade of meats from rare and endangered animals has decreased wild animals of their species in many countries.

\section{Vegan meat}

Artificial meat being free from all the vicissitudes of animals may be suitable for people who are vegetarians due to the ethical and cultural reasons.

\section{Space flights}

For current space missions, supply and physiochemical rejuvenation (of water and oxygen) are the major costeffective, but for longer periods and permanent bases, bio rejuvenation becomes more eye-catching Drysdale et al.
(2003). A controlled ecological life support system would not only provide unsoiled food to the astronauts, but also deal with waste and provide oxygen and water Saha and Trumbo (1996); Benjaminson et al. (1998); Drysdale et al. (2003). There are other situations also, like stations in Polar Regions, troop encampments in isolated theatres of war and bunkers designed for long-term survival of employees following a nuclear or biological assault, in which it is more economical to produce food in situ.

\section{Alternate source of protein}

Production of cultured meat supports the increasing needs of other protein sources. Unlike the other products, animalderived and with respect to composition most like meat. The reasons to produce cultured meat would be customer requirement as many more people are interested in newly proposed meat. Added to it, due to the non-sustainability of conventional meat production, there is a vast market for the in vitro meat. Other factors like prevention of food scarcity that can be expected with an increasing world population also favour the in vitro meat.

\section{Drawbacks and complications}

Even though, cultured meat is highly advocated by many people for its prospective environmental and climatic benefits and also favoured by animal ethics activists but simultaneously it has also generated doubts and censure reported Welin (2013).

\section{Sensory assessment}

The texture, colour and appearance of the cultured meat may have some problems in competing with the conventional meat. The cultured meat produced and tasted by a sensory panel in Riverside Studios in London in 2013 was reported to be colourless. The colour of the meat was improved by adding a bit of red beet juice and saffron analysed by Zaraska (2013). Thus new meat processing technologies have to be developed to improve the appearance and flavour of the developed cultured meat products. Cultured meat produced primarily included yolk-like splodge of selfassembling muscle fibres and tissue mono-layers harvested from scaffolds for preparation of communised meat products. On the other hand, many innovations are being attempted by using tissue engineering techniques to fabricate more appealing meat products by using scaffolds seeded with muscle cells that can firm up the resulting cultured meat. Scaffolds developed by using natural and edible biomaterials like collagen that allow for 3-D tissue culture and compound structuring of meat have also been proposed and attempted by Hopkins and Dacey (2008).

\section{Estrangement from nature}

An additionaldifficulty with the cultured meat production system is that it may estrange us from natural world and animals and can be a step in our move away from nature to live in cities. Cultured meat fits in with an increasing reliance on technology and the fret is that this comes with an ever 
Cultured Meat: The Upcoming Meat Production having Sustainable Benefits over Conventional Meat Production....

greater estrangement from nature suggested by Welin (2013). In the absence of livestock based farming, smaller areas of land will be affected by human activities which arefine for nature but it may at the same time estrange us from nature.

\section{Production cost and economic commotion}

The extremely high-priced cost of the cultured meat is the main probable obstacle, although large-scale production and market diffusion are usually associated with a striking price reduction. Bhat and Bhat (2011b). In vitro meat production on ancommercial scale is feasible only when a comparatively cost effective process showcasing a product qualitatively competitive with existing meat products established and provided with governmental subsidization like that provided to other agribusinesses. Bhat and Bhat (2011b). The cultured meat production will undoubtedly affect the economy of those nations which are involved in the conventional meat production on a wide scale and are reliant on the meat export. This technology will also affect the employment in the agricultural sector in countries where there is a large scale introduction of cultured meat production. Being close to the cities to limit the transport cost, these production centres will decrease the environmental pollution but conceivably it will not be so fine for countryside.

\section{Social and consumer acceptance}

Artificially developed cultured meat is being perceived as one of the strongest blockade for consumer acceptance. Welin (2013). Consumers are bothered about the aberrant character of cultured meat. But on the other hand, as Hopkins and Dacey state, "Just because something is natural, does not mean it is good for you". Hopkins and Dacey (2008); Schneider (2013). Further, people may feel cultured meat as artificial meat and not the real thing and as such they decrease in the valueof meat in the same way they would look down on artificial flowers or synthetic diamonds. Hopkins and Dacey (2008). People pay consideration to the reaction of revulsion in trying to judge whether a new and especially biotechnological, process is morally permissible and may it should be legally permissible. Kass (1997); Hopkins and Dacey (2008). Another oppositionis that already familiar from critiques of ethical vegetarianism and animals' lives will go better, paradoxically, in a world with something like the present meat production, than in a world with universal or widespread vegetarianism. Further argument is that in vitro meat shall use original cells gathered from some animal in a morally suspect way and that the use of such cells will morally contaminate all future generations of tissue. Hawthorne (2005); Hopkins and Dacey (2008).

\section{CONCLUSION}

Commercial meat production systems necessitate a relatively elevated proportion of land, energy and water and contribute to the emission of greenhouse gases. Inadequate nutrition-related diseases, foodborne illnesses, development of antibiotic-resistant pathogen strains and animal welfare issues are the other factors that are associated with the current meat production. Global meat consumption is expected to be doubled with $50 \%$ increase in the next 40 years and if no necessary actions are taken, it will be accompanied with an almost two fold increase in the greenhouse gas emissions and aggravating the environmental outcome of raising livestock. Production of artificial meat by culturing stem cells of domestic animal species seems to be one of the potential solutions. Cultured meat would provide healthy, nutritious and sustainable food for future generations for a rapidly increasing global population. Thus, cultured meat production holds great assurance as an alternative to conventional meat production systems, if provided with advancement in technology and made cost effective. Further research can be done on introduction and marketingof these products to build consumer's trust, acceptance with the product.

\section{REFERENCES}

Alexander, R. (2011). In vitro meat: A vehicle for the ethical rescaling of the factory farming industry and in vivo testing or an intractable enterprise? Intersect. 4: 42-47.

Bartholet, J. (2011). Inside the meat lab. Scientific American. 305: 65-69.

Benjaminson, M.A., Gilchriest, J.A., Lorenz, M. (2002). In vitro edible muscle protein production system (MPPS): Stage 1, fish. Acta Astronautica. 51: 879-889.

Benjaminson, M., Lehrer, S., Macklin, D. (1998). Bioconversion systems for food and water on long term space missions. Acta Astronautica. 43: 329-348.

Benjaminson, M.A., Gilchriest, J.A., Lorenz, M. (2002). In vitro edible muscle protein production system (MPPS): Stage 1, fish. Acta Astronautica. 15:116-121.

Bhat, Z.F., Bhat, H.F., Pathak, V. (2013). Prospects for in vitro Cultured Meat-A Future Harvest. In: Principles of Tissue Engineering, [Lanza, R., ed.], Fourth Edition. Elsevier Publication, USA. pp. 1663-1678.

Bhat, Z.F., Bhat, H. (2011a). Animal-free meat biofabrication. American Journal of Food Technology. 6: 441-459.

Bhat, Z.F., Bhat, H. (2011b). Prospectus of cultured meatadvancing meat alternatives. Journal of Food Science and Technology. 48: $125-140$.

Bhat, Z.F., Bhat, H. (2011c). Tissue engineered meat-future meat. Journal of Stored Products and Post-harvest Research. 2: $1-10$.

Bhat, Z.F., Bhat, H. (2011). Tissue Engineered Meat-Future Meat [Internet]. Vol. 2, Journal of Stored Products and Postharvest Research. 12: 63-78.

Boland, T., Mironov, V., Gutowska, A., Roth, E., Markwald, R. (2003). Cell and organ printing 2: Fusion of cell aggregates in threedimensional gels. The Anatomical Record. 272: 497-502.

Britt, R.R. (2002). Food of the future: Fish flesh grown without the fish. 2008: 5-13.

Catts, O., Zurr, I. (2002). Growing semi-living sculptures: The tissue culture project. Leonardo. 35: 365-370. 
Cultured Meat: The Upcoming Meat Production having Sustainable Benefits over Conventional Meat Production....

Chiles, R.M. (2013). Intertwined ambiguities: Meat, in vitro meat and the ideological construction of the marketplace. Journal of Consumer Behaviour. 20: 118-133.

Datar, I., Betti, M. (2010). Possibilities for an in vitro meat production system. Innovative Food Science and Emerging Techology. 11: 13-22.

Dennis, R., Kosnik, P.E. (2000). Excitability and isometric contractile properties of mammalian skeletal muscle constructs engineered in vitro. In vitro and Cellular Developmental Biology (Animal). 36: 327-335.

Drysdale, A., Ewert, M., Hanford, A. (2003). Life support approaches for mars missions. Advances in Space Research. 31: 51-61.

Edelman, P.D., McFarland, D.C., Mironov, V.A., Matheny, J.G. (2005). Commentary: In vitro-cultured meat production. Tissue Engineering. 11: 659-662.

Ford, B.J. (2010). Culturing Meat for the Future: Anti-Death Versus Anti-Life. In: Death and Anti-Death. [Tandy, C., ed.], Ria University Press, Palo Alto. Pp. 1-13.

Fox, J.L. (2009). Test tube meat on the menu?. Nature Biotechnology: 27: 873.

Hawthorne, M. (2005). From fiction to fork. Satya. 23: 56-81.

Hopkins, P.D., Dacey, A. (2008). Vegetarian meat: Could technology save animals and satisfy meat eaters?. Journal of Agricultural and Environmental Ethics. 21: 579-96.

Hukill, T. (2006). Would you eat lab-grown meat? Alternet. 2008: 5-13.

Jason Mathenyin. (2000). Carcinogenicity of consumption of red and processed meat. The lancet Oncology. 16: 1599-1608.

Kass, L. (1997). The wisdom of repugnance. The New Republic. 216: $17-26$.

Kosnik, P.E., Dennis, R.G., Vandenburgh, H.H. (2003). Tissue engineering skeletal muscle. In: Functional Tissue Engineering. [Guilak F, ed.], Springer-Verlag, New York. pp. 377-392.

Kuang, C. (2008). Farming in the sky. Popular Science. 273: 41.

Madrigal, A. (2008). Scientists flesh out plans to grow (and sell) test tube meat. Discovery News. 156:41-51.

Peterson, D. (2006). The in vitro cultured meat: No cows needed. In: The Catalyst Online. The Medical University of South Carolina, USA. Pp. 226.
Roberts. (2017). The in vitro cultured meat: No cows needed. In: The Catalyst Online. The Medical University of South Carolina, USA. 29:65-73.

Saha, P., Trumbo, P. (1996). The nutritional adequacy of a limited vegan diet for a controlled ecological life-support system. Advances in Space Research. 18: 63-72.

Sample, P. ( 2002). If you build it, will they eat it? Consumer preferences for plant-based and cultured meat burgers. Appetite. 125: 428-437.

Schneider, Z. (2013). In vitro meat: Space travel, cannibalism and federal regulation. Houston Law Review. 50: 991-1024.

Stephens, N., Di Silvio, L., Dunsford, I., Ellis, M., Glencross, A., Sexton, A. (2018). Bringing cultured meat to market: Technical, socio-political and regulatory challenges in cellular agriculture. Trends in Food Science and Technology. 78: $155-66$.

Tejas, Anupama. (2020). Glimpses on Lab-Grown Meat. Food and Agriculture Spectrum Journal. 01: 1-10

Tuomisto, H.L., Teixeira de Mattos, M.J. (2011). Environmental impacts of cultured meat production. Environmental Science and Technology. 45: 6117-6123.

Valin, H., Sands, R.D., van der Mensbrugghe, D., Nelson, G.C., Ahammad, H., Blanc, E., et al. (2014). The future of food demand: Understanding differences in global economic models. Agricultural Economics (United Kingdom). Jan; 45(1): 1-67. [Crossref] [PubMed] [Google Scholar].

Van Eelen, W.F., Van Kooten, W.J., Westerhof, W. (1999). Industrial production of meat from in vitro cell cultures. 66: 24

Welin, S. (2013). Introducing the new meat. Problems and Prospects. Nordic Journal of Applied Ethics. 7: 24-37.

Wolfson, W. (2002). Raising the steaks. New Scientist. 176: 60-63.

Zandonella, C. (2003). Tissue engineering: The beat goes on. Nature. 421: 884-886.

Zaraska, M. (2013). Lab-grown beef taste test: 'Almost' like a burger. pp. 23.

Zuhaib Fayaz, Bhat. (2015). Journal of Integrative Agriculture. 14(1): $241-248$ 